\title{
Uncaria rhynchophylla Ameliorates Parkinson's Disease by Inhibiting HSP90 Expression: Insights from Quantitative Proteomics
}

\author{
Yu-Long Lana Jun-Jun Zhou ${ }^{a}$ Jing Liu ${ }^{\mathrm{a}}$ Xiao-Kui Huo ${ }^{\mathrm{a}}$ Ya-Li Wanga,b \\ Jia-Hao Liang ${ }^{a}$ Jian-Chao Zhao a,c Cheng-Peng Sun ${ }^{a}$ Zhen-Long Yu ${ }^{a}$

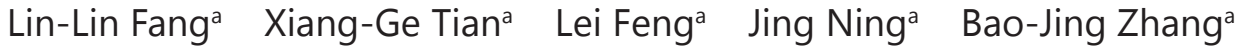 \\ Chao Wang ${ }^{\mathrm{a}}$ Xin-Yu Zhao ${ }^{\mathrm{a}}$ Xiao-Chi Ma ${ }^{\mathrm{a}}$
}

aCollege of Pharmacy, College (Institute) of Integrative Medicine, College of Medical Laboratory, Department of Neurosurgery, The Second Affiliated Hospital of Dalian Medical University, Dalian Medical University, Dalian, ${ }^{b} K e y$ Laboratory of Structure-Based Drug Design \& Discovery, Ministry of Education, Department of Natural Products Chemistry, School of Traditional Chinese Materia Medica, Shenyang Pharmaceutical University, Shenyang, 'School of Life Science and Biopharmaceutics, Shenyang Pharmaceutical University, Shenyang, China

\section{Key Words}

Uncaria rhynchophylla $•$ Parkinson's disease $\bullet$ Neuroprotective effect $•$ Proteomics $•$ HSP90

\begin{abstract}
Background/Aims: Uncaria rhynchophylla, known as "Gou-teng", is a traditional Chinese medicine (TCM) used to extinguish wind, clear heat, arrest convulsions, and pacify the liver. Although U. rhynchophylla has a long history of being often used to treat central nervous system (CNS) diseases, its efficacy and potential mechanism are still uncertain. This study investigated neuroprotective effect and the underlying mechanism of $U$. rhynchophylla extract (URE) in MPP+-induced SH-SY5Y cells and MPTP-induced mice. Methods: $\mathrm{MPP}^{+}$-induced SHSY5Y cells and MPTP-induced mice were used to established Parkinson's disease (PD) models. Quantitative proteomics and bioinformatics were used to uncover proteomics changes of URE. Western blotting was used to validate main differentially expressed proteins and test HSP90 client proteins (apoptosis-related, autophagy-related, MAPKs, PI3K, and AKT proteins). Flow cytometry and JC-1 staining assay were further used to confirm the effect of URE on MPP+induced apoptosis in SH-SY5Y cells. Gait analysis was used to detect the behavioral changes in MPTP-induced mice. The levels of dopamine (DA) and their metabolites were examined in striatum (STR) by HPLC-EC. The positive expression of tyrosine hydroxylase (TH) was detected by immunohischemical staining and Western blotting. Results: URE dose-dependently increased the cell viability in $\mathrm{MPP}^{+}$-induced $\mathrm{SH}-\mathrm{SY} 5 \mathrm{Y}$ cells. Quantitative proteomics and
\end{abstract}

Y.-L. Lan, J.-J. Zhou and J. Liu contributed equally to this work.

Cheng-Peng Sun

and Xiao-Chi Ma
College of Pharmacy, Dalian Medical University

No. 9, South Road of Lvshun, Dalian, 116044 (China)

Tel./Fax+86-0411-86110419, E-Mail suncp146@163.com, maxc1978@163.com 
bioinformatics results confirmed that HSP90 was an important differentially expressed protein of URE. URE inhibited the expression of HSP90, which further reversed MPP+-induced cell apoptosis and autophagy by increasing the expressions of Bcl-2, Cyclin D1, p-ERK, p-PI3K p85, PI3K p110 $\alpha$, p-AKT, and LC3-I and decreasing cleaved caspase 3, Bax, p-JNK, p-p38, and LC3-II. URE also markedly decreased the apoptotic ratio and elevated mitochondrial transmembrane potential $\left(\Delta \psi_{\mathrm{m}}\right)$. Furthermore, URE treatment ameliorated behavioral impairments, increased the contents of DA and its metabolites and elevated the positive expressions of TH in SN and STR as well as the TH protein. Conclusions: URE possessed the neuroprotective effect in vivo and in vitro, regulated MAPK and PI3K-AKT signal pathways, and inhibited the expression of HSP90. U. rhynchophylla has potentials as therapeutic agent in PD treatment.

(C) 2018 The Author(s)

Published by S. Karger AG, Basel

\section{Introduction}

Parkinson's disease (PD), the second most common neurodegenerative disorder [1], is caused by the progressive loss of dopaminergic neurons in the substantia nigra (SN) and affects more than $1 \%$ of the population over 65 years old [2-5]. However, the potential molecular mechanisms leading to neuronal degeneration in PD are still ambiguous. It is well known that some factors, such as apoptosis, mitochondrial dysfunction, neuroinflammation, oxidative stress, and endoplasmic reticulum stress, play critical roles in the cell death of nigrostriatal dopaminergic neurons in PD [6, 7]. Therefore, inhibition of the apoptosis and other factors have been given more attention in the therapeutic strategies for PD [8].

The genus Uncaria (Rubiaceae) comprises approximately 34 species mainly distributed in tropical regions, including Africa, Southeast Asia, and South America [9]. U. rhynchophylla, known as "Gou-teng" recorded in "Ming Yi Bie Lu": a famous monograph of traditional Chinese medicine (TCM) [10], has been used to extinguish wind, clear heat, arrest convulsions, and pacify the liver in China and Japan for thousands of years $[11,12]$. Recently, pharmacological investigations have indicated that $U$. rhynchophylla extract (URE) possesses neuroprotective effect against 6-hydroxydopamine (6-OHDA)-induced toxicity through antioxidative and antiapoptotic activities in PC12 cells and in 6-OHDA-lesioned rats [13]. However, its underlying mechanism and therapeutic target still remain unclear.

Quantitative proteomics techniques have recently been regarded as a reliable and precise method to reveal the discrepant protein expression and predict the disease-specific target and underlying mechanism of medicines [14]. In this study, the neuroprotective mechanism of URE was revealed by liquid chromatography-mass spectrometry based on stable isotopebased dimethyl labeling to discover the proteomics changes in MPP+-induced SH-SY5Y cells after URE administration. Then, a comprehensive bioinformatics analysis was conducted to figure the biological pathways in response to URE activation. We found that some key proteins, especially heat shock protein 90 (HSP90) in cell signaling might be involved in the neuroprotective effect of URE. The neuroprotective effect was further investigated in MPTPinduced Parkinson model mice to reveal the critical role of HSP90. Our study provided an experimental basis for clinical application of $U$. rhynchophylla in PD treatment.

\section{Materials and Methods}

Chemicals and reagents

$\mathrm{MPP}^{+}, \mathrm{MPTP}$, phosphate buffered saline (PBS), protease inhibitor cocktail, dopamine (DA), dihydroxyphenyl acetic acid (DOPAC), homovanillic acid (HVA), and cell counting kit-8 (CCK-8) were purchased from Sigma-Aldrich (St. Louis, MO). JC-1 staining kit, BCA proteins determining kit, and caspase-3 activity kit were purchased from Beyotime (Nanjing, China). The primary antibodies for HSP90AA1, HSP90AB1, $\beta$-actin, Bax, Bcl-2, ERK, p-ERK (Thr202/Tyr204), AKT, p-AKT (Ser473), p38, p-p38 (Tyr182), JNK, p-JNK (Tyr185), p-PI3K p85 (Tyr458), PI3K p110 $\alpha$, LC3-I/II, $\alpha$-Tubulin, LDHA, CCT4, YWHAE, AHCY, HSP70, HIST1H4A, H3F3A, TH, and all the secondary antibodies were obtained from Cell Signaling Technology (Beverly, MA, 


\section{Cellular Physiology Cell Physiol Biochem 2018;47:1453-1464 \begin{tabular}{c|c|c|} 
DOI: 10.1159/000490837 & $\begin{array}{l}\text { O 2018 The Author(s). Published by S. Karger AG, Basel } \\
\text { www.karger.com/cpb }\end{array}$
\end{tabular}}

Lan et al.: U. $r$ Ameliorates Parkinson's Disease by Inhibiting HSP90 Expression

USA). All other chemicals were purchased from Sigma Chemical Co. (St. Louis, MO). All remaining chemicals and reagents used in this experiment were analytic grade.

\section{Plant material and extract preparation}

Dried hooks of $U$. rhynchophylla were purchased in March 2017 from Beijing Tongrentang Co., Ltd., China, and identified by Prof. Jing-Ming Jia, Shenyang Pharmaceutical University. A voucher specimen (UR201703) has been deposited in the herbarium of the Department of Medicinal Chemistry, Dalian Medical University.

U. rhynchophylla powder (capable of passing a 4-mm sieve) was extracted with $95 \% \mathrm{EtOH}$ at $90{ }^{\circ} \mathrm{C}$ for $2 \mathrm{~h}$. The extract was evaporated in vacuo at $45^{\circ} \mathrm{C}$, then it was stored at $4{ }^{\circ} \mathrm{C}$.

\section{Cell culture}

Human neuroblastoma cells (SH-SY5Y) were purchased from American Type Culture Collection (ATCC, Manassas, VA, USA). The cells were maintained in 1640 medium (Gibco, NY, USA) with 10\% fetal bovine serum (FBS). All the cell cultures were maintained at $37{ }^{\circ} \mathrm{C}$ in a humidified atmosphere containing $5 \% \mathrm{CO}_{2}$.

\section{CCK-8 assay}

Briefly, SH-SY5Y cells were seeded in 96 -well plates at a density of $6 \times 10^{3}$ cells/well. Cells were allowed to adhere overnight before using fresh medium containing various concentrations of URE dissolved in DMSO (final concentration, $0.1 \%$ ). After the cells had been incubated with or without various concentrations of URE $(5,10$, or $20 \mu \mathrm{g} / \mathrm{mL})$ for $6 \mathrm{~h}$ followed by treatment with or without $\mathrm{MPP}^{+}(1 \mathrm{mM})$ for $24 \mathrm{~h}$, we measured their growth rates. CCK-8 was added per well and incubated for $1 \mathrm{~h}$ at $37^{\circ} \mathrm{C}$. The absorptions were recorded at $480 \mathrm{~nm}$ with a microplate reader. All experiments were performed in triplicate.

Annexin-V/Propidium iodide (PI) dual staining flow cytometric analysis.

Apoptosis was measured by a fluorescence-activated cell sorter (FACS) using an Annexin V-FITC Apoptosis Detection Kit (Nanjing Keygen Biotech. Co., Ltd.). Briefly, SH-SY5Y cells were plated in 6-well plates and then treated with the indicated doses of drugs. After treatment, the cells were collected and washed once with cold PBS before being stained simultaneously with FITC-labeled annexin V and PI, after which they were analysed using an FACS Accuri C6 (Genetimes Technology Inc.).

\section{Mitochondrial membrane potential assay}

A JC-1 probe was employed to measure mitochondrial depolarization in SH-SY5Y cells. Briefly, cells were cultured in six-well plates following treatment with URE $(20 \mu \mathrm{g} / \mathrm{mL})$ for $6 \mathrm{~h}$ and $\mathrm{MPP}^{+}(1 \mathrm{mM})$ for 24 h. Cells were then incubated with equal volumes of JC-1 staining solution $(5 \mu \mathrm{g} / \mathrm{mL})$ for 20 min at $37{ }^{\circ} \mathrm{C}$ before being rinsed twice with PBS. Mitochondrial membrane potential was monitored by measuring the relative amounts of dual emissions from mitochondrial JC-1 monomers or aggregates under Argon-ion 488 $\mathrm{nm}$ laser excitation using an Olympus fluorescence microscope. Mitochondrial depolarization was indicated by decreases in the red/green fluorescence intensity ratio.

\section{Western blotting analysis}

The cell lysate proteins were separated by electrophoresis on a 7.5-12\% sodium dodecyl sulfatepolyacrylamide minigel (SDS-PAGE) and then electrophoretically transferred to a PVDF membrane. The blots were probed with the appropriate specific antibodies, and the protein bands were detected by enhanced chemiluminescence. Similar experiments were performed at least three times. The total protein concentration was determined using a BCA Protein Assay Kit (Beyotime Biotechnology, China). The protein density values were determined by Image J (National Institutes of Health, Bethesda, MD). Percentages were expressed as percentages of the untreated groups $(100 \%)$.

\section{Stable isotope dimethyl labeling}

The digestions of human neuroblastoma cell proteins were prepared as previously described in literature [15]. The same amount of $\mathrm{MPP}^{+}$group sample and URE group sample were labeled by light labeling reagents $\left(5 \mathrm{mM} \mathrm{CH}_{2} \mathrm{O}\right.$ and $\left.5 \mathrm{mM} \mathrm{NaCNBH}{ }_{3}\right)$ and heavy labeling reagents $\left(5 \mathrm{mM} \mathrm{CD} \mathrm{C}_{2} \mathrm{O}\right.$ and $5 \mathrm{mM}$ $\mathrm{NaCNBH}_{3}$ ), respectively. And then, the light and heavy labeled samples were mixed together, desalted by a $\mathrm{C}_{18}$ solid-phase extraction column before lyophilized in a SpeedVac. 


\section{Cellular Physiology Cell Physiol Biochem 2018;47:1453-1464 \begin{tabular}{l|l} 
DOI: 10.1159/000490837 & $\begin{array}{l}\text { O 2018 The Author(s). Published by S. Karger AG, Basel } \\
\text { www.karger.com/cpb }\end{array}$
\end{tabular}}

Lan et al.: U. r Ameliorates Parkinson's Disease by Inhibiting HSP90 Expression

\section{LC-MS/MS analysis and database searching}

The samples were analysed by the SCX-RP multidimensional separation system and LTQ Orbitrap XL (Thermo, San Jose, CA) with Surveyor HPLC system. The samples were subjected to a SCX capillary trap column eluted with salt concentrations of 100, 200, 300, 400, 500, and $1000 \mathrm{mM} \mathrm{NH}_{4} \mathrm{Ac}(\mathrm{pH}$ 2.7). Each salt step lasted $10 \mathrm{~min}$ follow by 15 min equilibrium with $0.1 \%$ formic acid in water. Binary RP gradient elution from 5 to $35 \%\left(\mathrm{v} / \mathrm{v}\right.$ ) $\mathrm{CH}_{3} \mathrm{CN}$ in $130 \mathrm{~min}$. The MS and MS/MS spectra were collected by collision-induced dissociation (CID) at 35\% energy in a data dependent mode with $1 \mathrm{MS}$ scan from ranging from 400 to 2000 $\mathrm{m} / \mathrm{z}$ with the mass resolution of 60000 at $\mathrm{m} / \mathrm{z} 400$ in the Orbitrap analyzer followed by 6 MS/MS scans in the ion trap. The dynamic exclusion repeat count was 1 with a duration time of $30 \mathrm{~s}$, the exclusion list size was 500 with exclusion time of $90 \mathrm{~s}$, and the charge state rejection function was enabled to reject the ions with single and "unassigned" charge states.

The obtained raw files were searched with MaxQuant (Version 1.3.0.5) by using Uniprot protein fasta database of mouse (Downloaded from Uniprot website on June 15, 2016). Cysteine carboxamidomethylation was set as a static modification, methionine oxidation and acetylation of protein $N$-term were set as variable modifications with up to two missing cleavages of trypsin allowed. Precursor ion mass tolerances were 20 ppm, and fragment ion mass tolerance was $0.8 \mathrm{Da}$. The false discovery rate (FDR) for peptides and proteins were all set at $<1 \%$ and a minimum length of six amino acids was used for peptides identification. Doublets were selected as the quantification mode with the dimethyl Lys 0 and $N$-term 0 as light labels and dimethyl Lys 4 and $N$-term 4 as heavy labels. All other parameters were set at defaults in MaxQuant.

\section{Bioinformatics analysis}

Gene Ontology annotations including cellular component, biological process, and molecular function were performed with Blast2GO program (Version 2.7.0) [14, 16, 17]. A global protein-protein interaction network was generated using Cytoscape (Version 3.1) [18].

\section{Animal treatments}

C57BL/6 mice (23-25 g) were obtained from the Experimental Animal Center of Dalian Medical University (Dalian, China). All animal maintenance and treatment protocols were in accordance with local institutional guidelines for the care and use of laboratory animals. Mice were randomly divided into six groups $(n=8)$. Control group was given $0.5 \% \mathrm{CMC}-\mathrm{Na}$ for 19 days, and received the vehicle $\left(\mathrm{H}_{2} \mathrm{O}\right)$ alone from 8 th day to 12 th day. MPTP group was treated with $0.5 \%$ CMC-Na for 19 days, and administered MPTP (30 $\mathrm{mg} / \mathrm{kg}$, dissolved in $\left.\mathrm{H}_{2} \mathrm{O}\right)$ from 8 th day to 12 th day. The URE groups were administered URE $(20,40$, or 80 $\mathrm{mg} / \mathrm{kg}$, dissolved in $0.5 \% \mathrm{CMC}-\mathrm{Na}$ ) oral gavage of for 19 days, and administered with or without MPTP (30 $\mathrm{mg} / \mathrm{kg}$, dissolved in $\mathrm{H}_{2} \mathrm{O}$ ) from 8th day to 12 th day.

\section{Behavioral assessment-catwalk gait analysis}

The Catwalk automated gait analysis system (Noldus, Wageningen, Netherlands) was used to assess the gait and motor coordination according to our previous method [19].

Immunohistochemistry of tyrosine hydroxylase

The brain was quickly removed after the behavioral test and fixed with $10 \%$ formalin at $4{ }^{\circ} \mathrm{C}$ for $24 \mathrm{~h}$, then transferred to $30 \%$ sucrose solution for $24 \mathrm{~h}$. Substantia nigra (SN) and striatum (STR) samples were cut into $10 \mu \mathrm{m}$ thick sections (Leica, Germany) for the tyrosine hydroxylase (TH) immunohistochemistry assay according to our previous method [19]. TH-positive staining quantification was analysed using Image J software (National Institutes of Health, Bethesda, MD).

\section{HPLC-EC determination of DA and its metabolites}

HPLC analysis of DA, DOPAC, and HVA by electrochemical detection (HPLC-EC, Waters e2695 and 2465) was performed based on the previous method [20]. Briefly, dissected striata were homogenated and centrifuged at $12,000 \mathrm{~g}$ for $30 \mathrm{~min}$ at $4^{\circ} \mathrm{C}$. The supernatants were analysed for the contents of DA, DOPAC, and HVA by HPLC-EC. Their contents were calculated according to their calibration curves.

\section{Statistical analysis}

All the presented data were confirmed in at least three independent experiments and were expressed as the mean \pm SD. Statistical comparisons were made using one-way analysis of variance (ANOVA) followed by SPSS software. $P<0.05$ was considered statistically significant. 


\section{Cellular Physiology Cell Physiol Biochem 2018;47:1453-1464 and Biochemistry Published online: June 25, $2018 \quad$\begin{tabular}{l|l} 
DOI: 10.1159/000490837 2018 The Author(s). Published by S. Karger AG, Basel \\
www.karger.com/cpb
\end{tabular}}

Lan et al.: U. $r$ Ameliorates Parkinson's Disease by Inhibiting HSP90 Expression

\section{Results}

\section{URE suppressed MPP+-induced SH-SY5Y cell injury}

Effect of URE on MPP+-induced SH-SY5Y cell injury was studied by cell viability assay. $\mathrm{MPP}^{+}$possesses neurotoxicity, and it can cause dopaminergic neuron loss to mimic PD. $\mathrm{MPP}^{+}(1.0 \mathrm{mM}$ ) decreased cell viability to $45.56 \pm 3.15 \%$ (for all online suppl. material, see www.karger.com/doi/10.1159/000490837, Fig. S1 and Table S1), whereas pretreatment with URE $(5,10$, and $20 \mu \mathrm{g} / \mathrm{mL})$ significantly increased the cell viability $(50.11 \pm 4.93 \%$, $57.79 \pm 3.63 \%$, and $76.59 \pm 2.45 \%$ ) (see online suppl. material, Fig. S1 and Table S1). The morphological effect of URE on MPP+-induced SH-SY5Y cells was investigated by a brightfield microscope and DAPI staining assay. As shown in Fig. 1A, $\mathrm{MPP}^{+}$caused damage to the cells, which had become round with neurite retraction and membrane blebbing in the bright field, and had more fragmented nuclei in DAPI staining field (Fig. 1B). These alterations were ameliorated after URE pretreatment (Fig. 1A and 1B). These results suggested that URE could dose-dependently ameliorate the MPP+-induced SH-SY5Y cell injury.

\section{Effect of URE on proteome profile of MPP+-induced SH-SY5Y cells}

Quantitative proteomics techniques have recently been regarded as a reliable and precise method to reveal the discrepant proteins expression and predict the diseasespecific targets and underlying mechanism of natural products $[14,21]$. To decipher the neuroprotective mechanism of URE, stable isotope dimethyl labeling based on quantitative proteomics strategy was employed in triplicate. As a result, 459 proteins were quantified when controlling the RSD of the ratios for the quantified proteins to less than $50 \%$, of which, 22 proteins were quantified with at least a 2 -fold change with statistical significance $(p<0.05)$ (see online suppl. material, Table S2). Among these 22 differential proteins, 18 proteins were up-regulated (ratio $>2$ ) and 4 proteins were down-regulated (ratio $<0.5$ ) by the treatment of URE (see online suppl. material, Fig. S2).

\section{Gene ontology analysis of differentially expressed proteins}

To better characterize the 22 differentially expressed proteins, the Gene Ontology (G0) was performed with Blast2GO using standard parameters. The biological processes of the significantly differentially expressed proteins were most enriched in regulation of cellular, metabolic, single-organism, and biological process (see online suppl. material, Fig. S2). The categorical analysis of molecular function indicated that the majority of these proteins were classified into binding (45.65\%), catalytic activity (30.43\%), structural molecule activity $(13.04 \%)$, enzyme regulator activity $(6.52 \%)$, channel regulator activity $(2.17 \%)$, and nucleic acid binding transcription factor activity (2.17\%) (see online suppl. material, Fig. S2). Most of identified annotated proteins were located in the organelle, cell part, cell, extracellular region part, and extracellular region, respectively (see online suppl. material, Fig. S2).

Additionally, the protein-protein network of URE modulated proteins was analysed with Cytoscape network analysis. The network formed by the identified proteins provided insights into the potential mechanisms and biological processes that were regulated by URE. In this study, 22 proteins could be link together into one network through direct interaction (Fig. 2), revealing their inherent correlation. These interacting proteins include the ribosome proteins and metabolic process proteins. Several differentially expressed proteins, such as

Fig. 1. (A) Effects of $\mathrm{MPP}^{+}(1 \mathrm{mM})$ only and URE $(20 \mu \mathrm{g} / \mathrm{mL})$ together with $\mathrm{MPP}^{+}(1 \mathrm{mM})$ on cell morphology, bright-field and DAPI staining images. (B) The ration of fragment and round cells. ${ }^{* *} \mathrm{p}<0.01$ compared with control group, ${ }^{\# \#} \mathrm{p}<0.01$ compared with $\mathrm{MPP}^{+}$group.

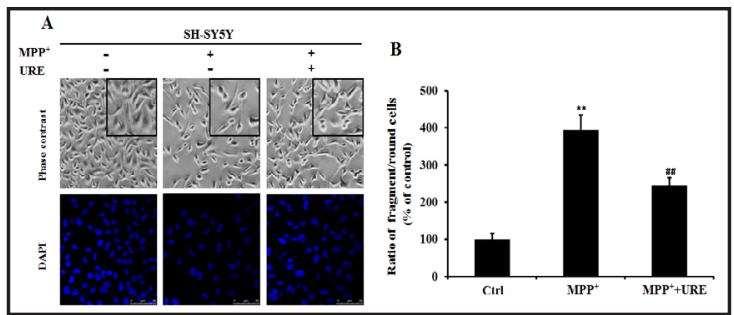


Lan et al.: U. $r$ Ameliorates Parkinson's Disease by Inhibiting HSP90 Expression

HSP90AA1, HSP90AB1, CCT4, and LDHA, were identified as multiple central nodes, which might serve as the important proteins for the neuroprotective activity of URE.

\section{Confirmation of differentially expressed proteins by Western blotting}

Western blotting assay was then used to validate the expressions of the main identified proteins. As shown in Fig. 3, $\alpha$-Tubulin, LDHA, CCT4, YWHAE, and AHCY were found to be upregulated, whereas HSP90AA1, HSP90AB1, HIST1H4A, and H3F3A were found to be downregulated after URE administration in $\mathrm{MPP}^{+}$treated $\mathrm{SH}-\mathrm{SY} 5 \mathrm{Y}$ cells, which were identical to the proteomics results.

\section{Western blotting analysis of HSP90 client proteins}

HSP90AA1 and HSP90AB1, with significant interactions with other differentially expressed proteins, were the key central nodes according to the protein-protein network (see online suppl. material, Fig. S2 and Table S3). Previous studies have indicated that HSP90 plays an important role in the anti-PD field [22-24], therefore, HSP90AA1 and HSP90AB1 were speculated to be two critical proteins affected by URE treatment in $\mathrm{MPP}^{+}$-induced SHSY5Y cells. HSP90, as a molecular chaperone, played an indispensable role in normal cellular homeostasis by regulating the folding, stability, and function of its client proteins, some of which have effects in regulating signal transduction pathways. Thus, the expressions of HSP90 client proteins, such as p-p38, p-JNK, p-ERK, p-PI3K p85, PI3K p110 $\alpha$, p-AKT, CDK4, Cyclin D1, and VEGF $[25,26]$, were analysed by Western blotting. The expression levels of CDK4, Cyclin D1, VEGF, p-ERK, p-PI3K p85, PI3K p110 $\alpha$, and p-AKT significantly decreased in the $\mathrm{MPP}^{+}$group, and the expression levels of JNK and p38 were significantly increased in the $\mathrm{MPP}^{+}$group. However, these results were reversed in the URE group (Fig. 4).

\section{Effects of URE on MPP+-} induced cell apoptosis and autophagy

MAPKs, PI3K, and AKT proteins, as important HSP90 client proteins, can regulate apoptosis-related and autophagy-related proteins, such as cleaved caspase 3, Bcl-2, Bax, and LC3, which indicates that they played critical roles in cell apoptosis and autophagy [27-29]. In order

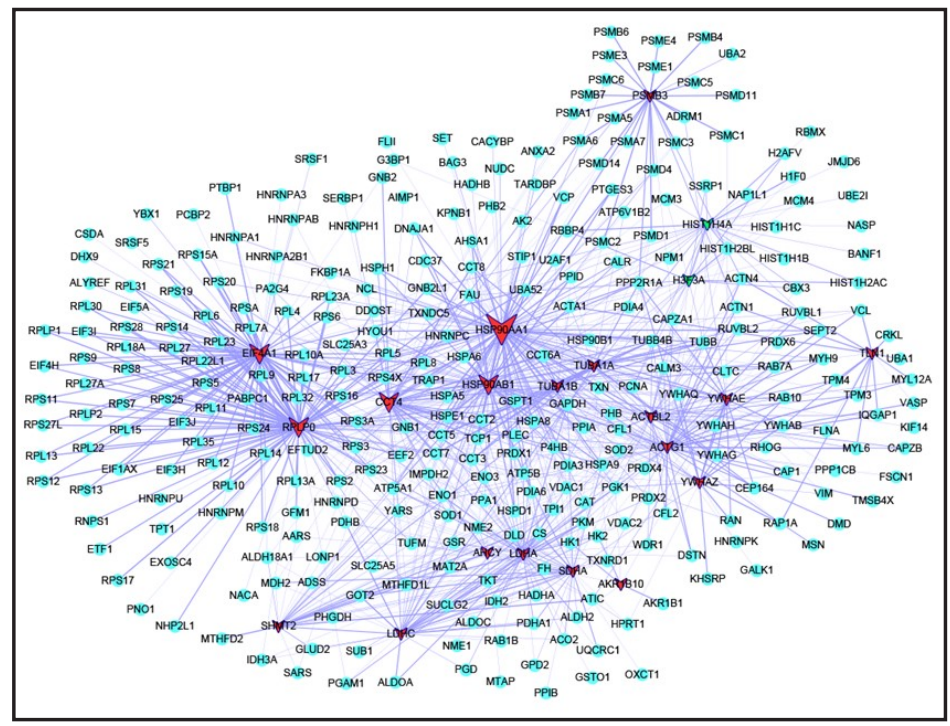

Fig. 2. The interaction network of the 22 differentially expressed proteins.

Fig. 3. (A) Western blotting of $\alpha$-Tubulin, LDHA, CCT4, YWHAE, AHCY, HSP90AA1, HSP90AB1, HSP70, HIS1H4A, and H3F3A. (B) Quantitative data of (A). ${ }^{* *} \mathrm{p}<0.01$ compared with control group, $\#$ $\mathrm{p}<0.01$ compared with $\mathrm{MPP}^{+}$ group.

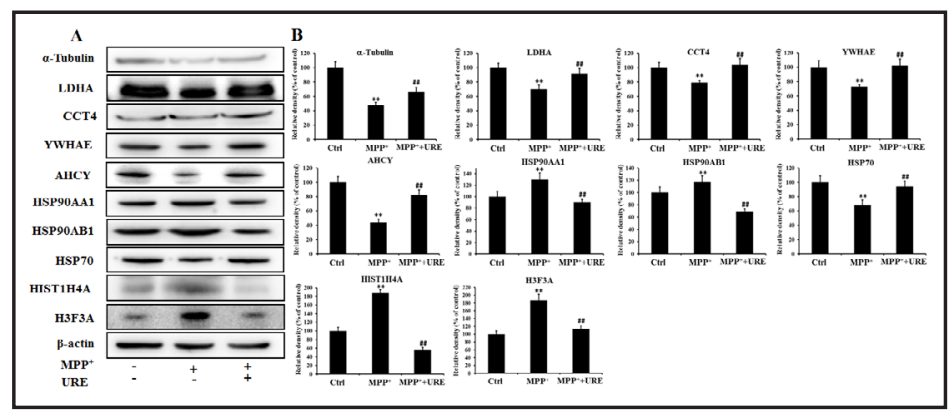


Fig. 4. (A) Western-blotting analysis of HSP90 client proteins. (B) Quantitative data of $(\mathrm{A}) .{ }^{* *} \mathrm{p}<0.01$ compared with control group, ${ }^{\#} \mathrm{p}<0.01$ compared with $\mathrm{MPP}^{+}$ group.

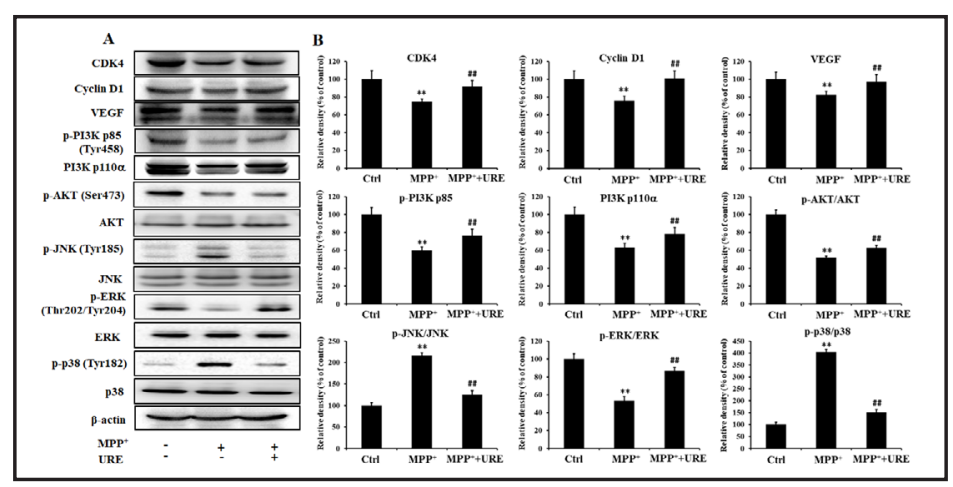

Fig. 5. (A) Results of Annexin-V/PI binding assay through flow cytometry for untreated control, $\mathrm{MPP}^{+}$ (1 $\mathrm{mM})$, and URE (20 $\mu \mathrm{g} / \mathrm{mL})$ plus $\mathrm{MPP}^{+}$(1 mM). (B) Apoptotic cell ratio. (C) JC-1 staining assay for untreated control, $\mathrm{MPP}^{+}(1 \mathrm{mM})$, and URE $(20 \mu \mathrm{g} / \mathrm{mL})$ plus $\mathrm{MPP}^{+}$ (1 mM). (D) The ratio of intensity of red to green indicating the changes in $\Delta \psi_{\mathrm{m}}$. (E) Effects of URE on the expression of apoptosis-related and autophagy-related proteins (F) Quantitative data of (E), ${ }^{* *} \mathrm{p}<0.01$ compared with control group, ${ }^{\#} \mathrm{p}<0.01$ compared with $\mathrm{MPP}^{+}$group.

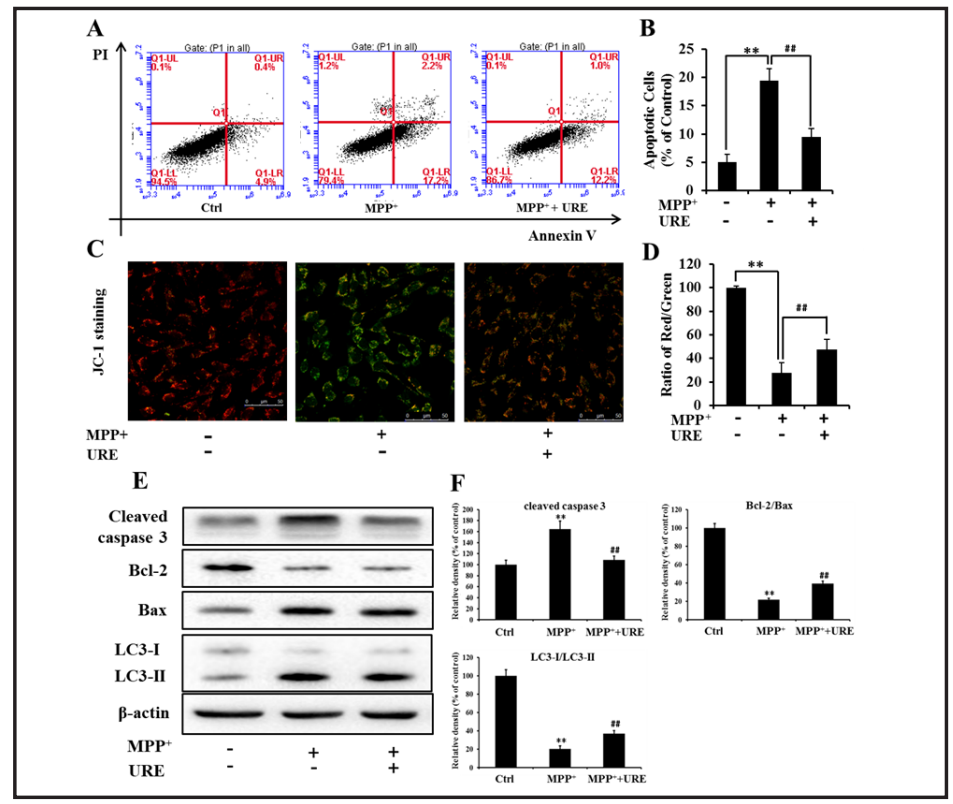

to evaluate the effects of URE in cell apoptosis and autophagy, Western blotting and JC-1 staining were performed.

Flow cytometry was conducted to confirm the effect of URE on MPP+-induced apoptosis in SH-SY5Y cells. These results indicated that URE markedly decreased the apoptotic ratio in SH-SY5Y cells treated by MPP+ (Fig. 5A and 5B).

The mitochondrial transmembrane potential, which is an important biochemical hallmark of apoptosis, was detected by JC-1 staining assay in order to assay the effect of URE on mitochondrial activity [29,30]. As shown in Fig. 5C and 5D, high green and low red fluorescence intensity presented in $\mathrm{MPP}^{+}$-induced cells, suggesting mitochondrial depolarization. However, the above phenomenon was significantly reversed after pretreatment with URE. The actual $\Delta \psi_{\mathrm{m}}$ changes were quantified on the basis of the relative intensity of red vs. green fluorescence in the adequate groups (Fig. 5C and 5D). It was proved that URE could inhibit MPP+-induced apoptosis to protect MPP+-induced damage.

The mitochondrial apoptosis pathway is mainly involved in the apoptosis of dopaminergic neuronal cells. The biochemical hallmarks of apoptosis, such as cleaved caspase 3, Bax, and Bcl-2, were detected by Western blotting analysis [29, 30]. The expressions of cleaved caspase 3 and Bax remarkedly increased whereas the expression of Bcl-2 decreased after $\mathrm{MPP}^{+}(1 \mathrm{mM})$ administration. After the cells being treated with URE, the expressions of cleaved caspase 3 and Bax decreased, and the expression of Bcl-2 increased (Fig. 5E and 5F), indicating that URE possessed the protective activity on MPP'-induced damage in SH-SY5Y cells by inbition of $\mathrm{MPP}^{+}$-induced apoptosis. 
Autophagy, a potential drug target for the treatment of PD, could protect neurons from injuries [31, 32]. In order to confirm the effect of URE on autophagy, autophagy biomarkers LC3-I and LC3-II were detected by Western blotting analysis. The expression of LC3-I decreased whereas the expression of LC3-II increased after $\mathrm{MPP}^{+}(1 \mathrm{mM})$ administration. The opposite results were observed after URE pretreament. (Fig. 5E and 5F), indicating that URE could induce autophagy.

\section{URE improved MPTP-induced gait disorders}

MPTP has been the most effective neurotoxin for inducing PD model of animals. Therefore, the inhibition of URE on HSP90 was detected in MPTP-induced mouse model.

Gait was generally disturbed in animals upon damage of dopaminergic neuron, and it could directly reflect the subtle changes in motor behavior [33, 34]. To assess the effect of URE against MPTP-induced gait disorders, some gait parameters were measured on Catwalk automated gait analysis system, including duration, maximum variation, average speed, and cadence. As shown in (Fig. 6), MPTP treatment prolonged the duration and maximum variation, and decreased average speed and cadence. The impairment of gait behavior was dose-dependently ameliorated by URE treatment, suggesting that URE could improve behavioral impairments induced by MPTP.

Effects of URE on the levels of DA, DOPAV, and HVA in STR

In order to detect the levels of DA and its metabolites in STR, HPLC-EC was used to analyse the effect of URE against DA and its metabolites. The administration of MPTP decreased in the levels of dopamine and its metabolites compared with the control group, whereas the URE treatment significantly attenuated the decrease in their levels (Fig. 7).

URE attenuated dopaminergic neuronal loss of SN and STR in MPTPinduced mouse model

$\mathrm{TH}$ is a critical marker of dopaminergic neurons, thus, SN and STR were immunostained to assay for the neuroprotective effect of URE in vivo model. The MPTP group showed significantly fewer TH-positive cells and fibers than the control group. However,

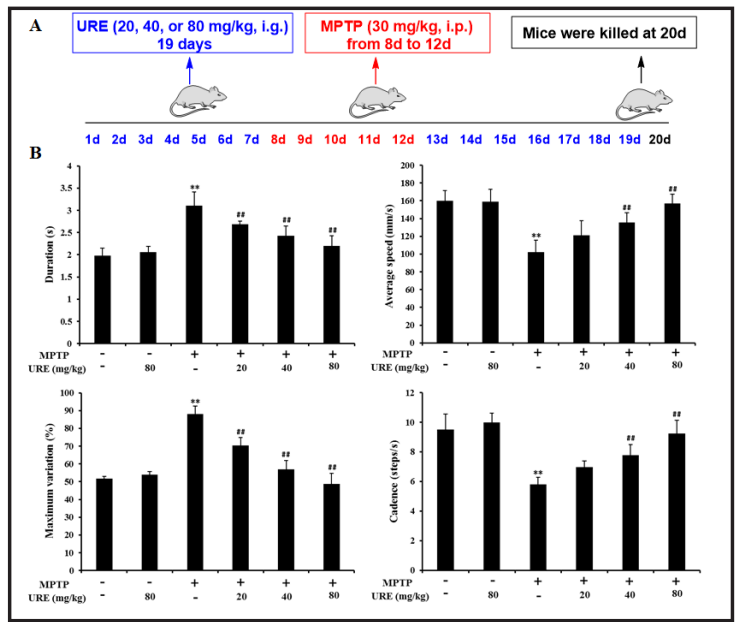

Fig. 6. Effects of URE on the behavioristics of MPTP-induced mice model. (A) The flow chart of experiments. (B) The behavioristics parameters, ${ }^{* *} \mathrm{p}<0.01$ compared with control group, ${ }^{\#} \mathrm{p}<0.01$ compared with MPTP group.
Fig. 7. Representative microphotographs of $\mathrm{TH}$ immunostaining of $\mathrm{SN}$ and STR (A), quantitative data of SN (B) and STR (C), and effects of URE treatment on contents of DA, DOPAC, and HVA in STR after MPTP treatment (D), ${ }^{* *} \mathrm{p}<0.01$ compared with control group, ${ }^{\# \#} \mathrm{p}<0.01$ compared with MPTP group.

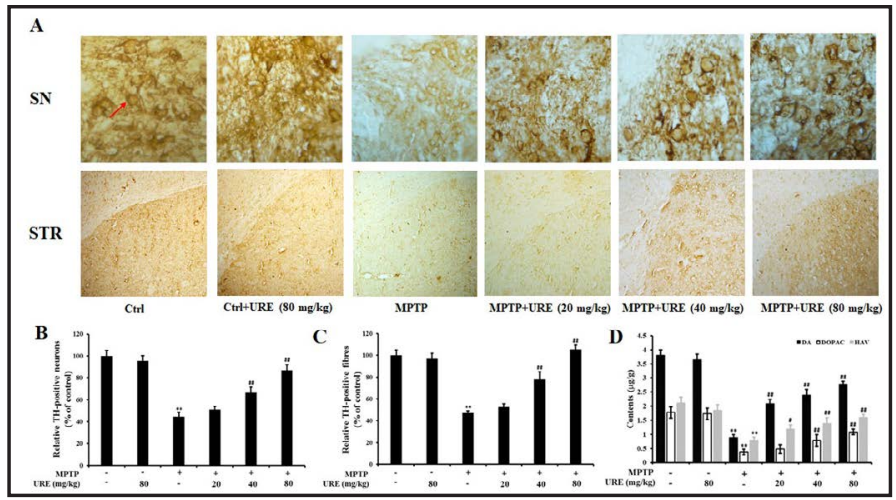


Fig. 8. (A) Western blot of $\mathrm{TH}$, HSP90AA1, HSP90AB1, and HSP70 in the SN. (B) Quantitative data of (A). ${ }^{* *} \mathrm{p}<0.01$ compared with control group, ${ }^{*} \mathrm{p}<0.05$ compared with MPTP group, ${ }^{\# \#} \mathrm{p}<0.01$ compared with MPTP group.

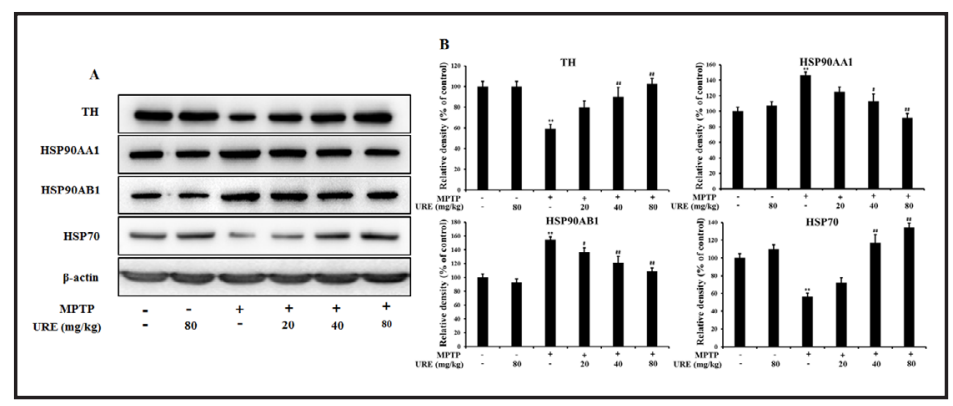

pretreatment with URE could dose-dependently prevent the loss of TH-positive cells in SN and the loss of TH-positive fibers in STR (Fig. 7). The expression of TH was significantly down-regulated in the MPTP group, whereas pretreatment with URE could dose-dependently attenuate MPTP-induced TH loss in SN (Fig. 7). These results showed that URE protected against MPTP-induced dopaminergic neuronal loss.

\section{URE suppressed the expression of HSP90 in vivo model}

According to the above-mentioned in vitro results, URE had the neuroprotective activity through inhibition on HSP90. Therefore, the inhibitory effect of URE on HSP90 was confirmed in vivo model. The expression levels of HSP90AA1 and HSP90AB1 were significantly increased in MPTP group (Fig. 8), whereas their expression levels were dose-dependently decreased by URE treatment, indicating that URE could suppress the expression of HSP90 to ameliorate PD in vivo.

\section{Discussion}

Some evidences have indicated that URE possess a promising role in neuroprotective effect through anti-apoptosis and antioxidative stress $[13,35]$. An understanding of the mechanisms and drug targets of this neuroprotective effect will be beneficial to develop effective ways for improving or preventing the progression of PD. Therefore, in our present study, proteomics and bioinformatics were investigated in both $\mathrm{MPP}^{+}$-induced cell injury and MPTP-induced PD models. We first reported that URE possessed anti-apoptotic and inducedautophagy effects through MAPK and PI3K-AKT signal pathways via HSP90 inhibition.

HSP90 has been recently identified as the predominant chaperone implicated in $\alpha$-synuclein-induced PD pathologies [36, 37], which could prevent $\alpha$-synuclein misfolding, oligomerization, and aggregation to suppress $\alpha$-synuclein misfolding-induced PD toxicity [38]. In addition, HSP90 could regulate the proliferative and senescent client proteins [14], including PI3K, AKT, MAPKs, CDK4, Cyclin D1, and VEGF, which also indicated that HSP90 played an important role in the PD $[24,25,38,39]$. Quantitative proteomics technique is a reliable and precise method to predict the disease-specific targets and underlying mechanism [21]. In order to clarify the mechanism of URE, we employed quantitative proteomics techniques. Our proteomic and bio-informational analysis results suggested that HSP90 might involve in the effect of URE, and the profile of protein-protein network also revealed that it played a critical role in all identified proteins. Our results indicated that URE could suppress the expression of HSP90 to ameliorate PD.

Damages of dopaminergic neurons could lead to the production of neuron apoptosis, and then cause PD [19]. MAPKs, PI3K, and AKT, as HSP90 client chaperones, could regulate cell apoptosis, autophagy, proliferation, neural plasticity, and cell survival, indicating that MAPK and PI3K-AKT signal pathways played critical roles in the nervous system [40-42]. Previous studies suggested that the apoptosis-related and autophagy-related proteins, such as Bcl-2, Bax, LC3, and cleaved caspase 3, involved in the MAPKs and PI3K-AKT signal pathways. Therefore, HSP90 client proteins MAPKs, PI3K, and AKT proteins were detected 
by Western blot together with apoptosis-related and autophagy-related proteins Bcl-2, Bax, LC3, and cleaved caspase 3. Our results indicated that URE could protect MPP+-induced cell injury through inhibition on apoptosis and induction of autophagy via MAPK and PI3K-AKT signal pathways.

To further evaluate the neuroprotective effect of URE in vivo, we employed MPTPinduced mouse model. Gait was generally disturbed in animals upon damage of dopaminergic neuron, and the expression level of $\mathrm{TH}$ as a rate-limiting enzyme in the DA biosynthesis also reflected whether there was the damage of dopaminergic neuron $[19,43]$. Therefore, some gait parameters and the expression level of TH were detected. MPTP treatment prolonged the duration and maximum variation, decreased average speed, cadence, and the expression level of TH, whereas the above results were reversed in URE group. In order to assay the inhibitory effect of URE on HSP90, Western blotting was used. The expression levels of HSP90AA1 and HSP90AB1 were significantly increased in MPTP group, whereas their expression levels were dose-dependently decreased by URE treatment. The abovementioned results demonstrated that URE has neuroprotective effect against MPTP-induced dopaminergic neurodegeneration in mice through inhibition on HSP90 expression.

\section{Conclusion}

In this study, quantitative proteomics and bioinformatics were used to investigate the in vitro mechanism of URE in PD. Our results strongly showed that URE possessed neuroprotective effect including anti-apoptosis and induction of autophagy. URE could regulate MAPK and PI3K-AKT signal pathways, and inhibit the expression of HSP90. The in vivo result further confirmed that URE exerted anti-PD effect via inhibition of HSP90 expression.

\section{Acknowledgements}

This work is supported by the National Natural Science Foundation of China (No. 81703679, 81622047, and 81503201), Dalian Outstanding Youth Science and Technology Talent (2015J12JH201), Distinguished professor of Liaoning Province, Liaoning BaiQianWan Talents Program, Innovation Team of Dalian Medical University, and Natural Science Foundation of College (Institute) of Integrative Medicine of Dalian Medical University (ICIM2017001).

\section{Disclosure Statement}

The authors have declared that they have no competing interests.

\section{References}

1 Hernando S, Herran E, Figueiro-Silva J, Pedraz JL, Igartua M, Carro E, Hernandez RM: Intranasal administration of TAT-conjugated lipid nanocarriers loading GDNF for Parkinson's disease. Mol Neurobiol 2018;55:145-155.

-2 Yu ZL, Peng YL, Wang C, Cao F, Huo XK, Tian XG, Feng L, Ning J, Zhang BJ, Sun CP, Ma XC: Alismanoid A, an unprecedented 1, 2-seco bisabolene from Alisma orientale, and its protective activity against $\mathrm{H}_{2} \mathrm{O}_{2}$-induced damage in SH-SY5Y cells. New J Chem 2017;41:12664-12670.

- 3 Fornai F, Soldani P, Lazzeri G, di Poggio AB, Biagioni F, Fulceri F, Batini S, Ruggieri S, Paparelli A: Neuronal inclusions in degenerative disorders - Do they represent static features or a key to understand the dynamics of the disease? Brain Res Bull 2005;65:275-290. 


\section{Cellular Physiology Cell Physiol Biochem 2018;47:1453-1464 \begin{tabular}{l|l} 
DOI: 10.1159/000490837 & $\begin{array}{l}\text { O 2018 The Author(s). Published by S. Karger AG, Basel } \\
\text { www.karger.com/cpb }\end{array}$
\end{tabular}}

Lan et al.: U. $r$ Ameliorates Parkinson's Disease by Inhibiting HSP90 Expression

4 Huang Y, Liu Z, Cao BB, Qiu YH, Peng YP: Treg cells protect dopaminergic neurons against MPP+ neurotoxicity via CD47-SIRPA interaction. Cell Physiol Biochem 2017;41:1240-1254.

5 Moore DJ, West AB, Dawson VL, Dawson TM: Molecular pathophysiology of Parkinson's disease. Annu Rev Neurosci 2005;28:57-87.

6 Liu H, Mao P, Wang J, Wang T, Xie CH: Allicin protects PC12 cells against 6-OHDA-induced oxidative stress and mitochondrial dysfunction via regulating mitochondrial dynamics. Cell Physiol Biochem 2015;36:966979.

-7 Liu YY, Liao ST, Quan HY, Lin YH, Li J, Yang QS: Involvement of microRNA-135a-5p in the protective effects of hydrogen sulfide against Parkinson's disease. Cell Physiol Biochem 2016;40:18-26.

-8 Aminzadeh MA, Sato T, Vaziri ND: Participation of endoplasmic reticulum stress in the pathogenesis of spontaneous glomerulosclerosis-Role of intra-renal angiotensin system. Translat Res 2012;160:309-318.

9 Zhang Q, Zhao JJ, Xu J, Feng F, Qu W: Medicinal uses, phytochemistry and pharmacology of the genus Uncaria. J Ethnopharmacol 2015;173:48-80.

10 Apfel CM, Evers S, Hubschwerlen C, Pirson W, Page MG, Keck W: Peptide deformylase as an antibacterial drug target: assays for detection of its inhibition in Escherichia coli cell homogenates and intact cells. Antimicrob. Agents Chemother 2001;45:1053-1057.

11 Geng CA, Huang XY, Ma YB, Hou B, Li TZ, Zhang XM, Chen JJ: (+/-)-Uncarilins A and B, Dimeric isoechinulintype alkaloids from Uncaria rhynchophylla. J Nat Prod 2017;80:959-964.

12 Li RX, Cheng JT, Jiao MJ, Li L, Guo C, Chen S, Liu A: New phenylpropanoid-substituted flavan-3-ols and flavonols from the leaves of Uncaria rhynchophylla. Fitoterapia 2017;116:17-23.

13 Shim JS, Kim HG, Ju MS, Choi JG, Jeong SY, Oh MS: Effects of the hook of Uncaria rhynchophylla on neurotoxicity in the 6-hydroxydopamine model of Parkinson's disease. J Ethnopharmacol 2009;126:361365.

14 Zhang LY, Yu ZL, Wang Y, Wang XB, Zhang LR, Wang C, Yue QX, Wang X, Deng S, Huo XK, Tian XG, Huang SS, Zhang BJ, Ma XC: Quantitative proteomics reveals molecular mechanism of gamabufotalin and its potential inhibition on Hsp90 in lung cancer. Oncotarget 2016;7:76551-76564.

15 Liu J, Wang FJ, Lin H, Zhu J, Bian YY, Cheng K, Zou HF: Monolithic capillary column based glycoproteomic reactor for high-sensitive analysis of $\mathrm{N}$-glycoproteome. Anal Chem 2013;85:2847-2852.

16 Conesa A, Gotz S, Garcia-Gomez JM, Terol J, Talon M, Robles M: Blast2GO: a universal tool for annotation, visualization and analysis in functional genomics research. Bioinformatics 2005;21:3674-3676.

17 Gotz S, Garcia-Gomez JM, Terol J, Williams TD, Nagaraj SH, Nueda MJ, Robles M, Talon M, Dopazo J, Conesa A: High-throughput functional annotation and data mining with the Blast2GO suite. Nucleic Acids Res 2008;36:3420-3435.

18 Enjalbert B, Jourdan F, Portais JC: Intuitive visualization and analysis of multi-omics data and application to Escherichia coli carbon metabolism. PLoS One 2011;6:e21318.

19 Xu T, Zhou JJ, Zhu J, Zhang S, Zhang N, Zhao Y, Ding CC, Shi X, Yao JJ: Carnosic acid protects non-alcoholic fatty liver-induced dopaminergic neuron injury in rats. Metab Brain Dis 2017;32:483-491.

20 Richardson JR, Caudle WM, Wang MZ, Dean ED, Pennell KD, Miller GW: Developmental exposure to the pesticide dieldrin alters the dopamine system and increases neurotoxicity in an animal model of Parkinson's disease. FASEB J 2006;20:1695-1697.

21 Yin LH, Qi Y, Xu YW, Xu LN, Han X, Tao XF, Song SS, Peng JY: Dioscin inhibits HSC-T6 cell migration via adjusting SDC-4 expression: Insights from iTRAQ-based quantitative proteomics. Front Pharmacol 2017;8:665.

22 Aridon P, Geraci F, Turturici G, D’Amelio M, Savettieri G, Sconzo G: Protective role of heat shock proteins in Parkinson's disease. Neurodegenerative Diseases 2011;8:155-168.

23 Haase M, Fitze G: HSP90ABl: Helping the good and the bad. Gene 2016;575:171-186.

24 Lackie RE, Maciejewski A, Ostapchenko VG, Marques-Lopes J, Choy WY, Duennwald ML, Prado VF, Prado MAM: The Hsp70/Hsp90 chaperone machinery in neurodegenerative diseases. Front Neurosci 2017;11:254

25 Miyata Y, Ikawa Y, Shibuya M, Nishida E: Specific association of a set of molecular chaperones including HSP90 and Cdc37 with MOK, a member of the mitogen-activated protein kinase superfamily. J Biol Chem 2001;276:21841-21848.

26 Bates WR: HSP90 and MAPK activation are required for ampulla development in the direct-developing 


\section{Cellular Physiology Cell Physiol Biochem 2018;47:1453-1464 \begin{tabular}{l|l} 
DOI: 10.1159/000490837 & $\begin{array}{l}\text { O 2018 The Author(s). Published by S. Karger AG, Basel } \\
\text { www.karger.com/cpb }\end{array}$
\end{tabular}}

Lan et al.: U. r Ameliorates Parkinson's Disease by Inhibiting HSP90 Expression

ascidian Molgula pacifica. Invertebr Biol.2007;126:90-98.

27 Jung JY, Il Yoo C, Kim HT, Kwon CH, Park JY, Kim YK: Role of mitogen-activated protein kinase (MAPK) in troglitazone-induced osteoblastic cell death. Toxicology 2007;234:73-82.

28 Kim BJ, Ryu SW, Song BJ: JNK- and p38 kinase-mediated phosphorylation of Bax leads to its activation and mitochondrial translocation and to apoptosis of human hepatoma HepG2 cells. J Biol Chem 2006;281:21256-21265.

29 Hu XL, Song Q, Li X, Li DD, Zhang Q, Meng WH, Zhao QC: Neuroprotective effects of kukoamine A on neurotoxin-induced Parkinson's model through apoptosis inhibition and autophagy enhancement. Neuropharmacology 2017;117:352-363.

-30 Cao Q, Qin LY, Huang F, Wang XS, Yang L, Shi HL, Wu H, Zhang BB, Chen ZY, Wu XJ: Amentoflavone protects dopaminergic neurons in MPTP-induced Parkinson's disease model mice through PI3K/Akt and ERK signaling pathways. Toxicol Appl Pharmacol 2017;319:80-90.

-31 Jin HQ Lei JZ: A mathematical model of cell population dynamics with autophagy response to starvation. Math Biosci 2014;258:1-10.

-32 Wang LQ Wang Y, Gao SY, Zhu LH, Wang F, Li H, Chen LX: Phenolic amides with anti-Parkinson's disease (PD) effects from Nicandra physaloides. J Funct Foods 2017;31:229-236.

33 Chuang CS, Su HL, Cheng FC, Hsu SH, Chuang CF, Liu CS: Quantitative evaluation of motor function before and after engraftment of dopaminergic neurons in a rat model of Parkinson's disease. J Biomed Sci 2010;17:9.

34 Saal KA, Koch JC, Tatenhorst L, Szego EM, Ribas VT, Michel U, Bahr M, Tonges L, Lingor P: AAV.shRNAmediated downregulation of ROCK2 attenuates degeneration of dopaminergic neurons in toxin-induced models of Parkinson's disease in vitro and in vivo. Neurobiol Dis 2015;73:150-162.

-35 Qi W, Yue SJ, Sun JH, Simpkins JW, Zhang L, Yuan D: Alkaloids from the hook-bearing branch of Uncaria rhynchophylla and their neuroprotective effects against glutamate-induced HT22 cell death. J Asian Nat Prod. Res. 2014;16:876-883.

-36 Inda C, Bolaender A, Wang T, Gandu SR, Koren J: Stressing out Hsp90 in neurotoxic proteinopathies. Curr Top Med Chem 2016;16:2829-2838.

37 Jones DR, Moussaud S, McLean P: Targeting heat shock proteins to modulate alpha-synuclein toxicity. Ther Adv Neurol Disord 2014;7:33-51.

-38 Xiong R, Zhou WB, Siegel D, Kitson RRA, Freed CR, Moody CJ, Ross D: A Novel Hsp90 inhibitor activates compensatory heat shock protein responses and autophagy and alleviates mutant A53T alpha-synuclein toxicity. Mol Pharmacol 2015;88:1045-1054.

39 Xie H, Hu H, Chang M, Huang D, Gu X, Xiong X, Xiong R, Hu L, Li G: Identification of chaperones in a MPP(+)induced and ATRA/TPA-differentiated SH-SY5Y cell PD model. Am J Transl Res 2016;8:5659-5671.

40 Nelson ED, Ramberg JE, Best T, Sinnott RA: Neurologic effects of exogenous saccharides: A review of controlled human, animal, and in vitro studies. Nutr Neurosci 2012;15:149-162.

41 Wei WL, Zeng R, Gu CM, Qu Y, Huang LF: Angelica sinensis in China-A review of botanical profile, ethnopharmacology, phytochemistry and chemical analysis. J Ethnopharmacol.2016;190:116-141.

-42 Bryant DN, Sheldahl LC, Marriott LK, Shapiro RA, Dorsa DM: Multiple pathways transmit neuroprotective effects of gonadal steroids. Endocrine 2006;29:199-207.

43 Michely J, Volz LJ, Barbe MT, Hoffstaedter F, Viswanathan S, Timmermann L, Eickhoff SB, Fink GR, Grefkes C: Dopaminergic modulation of motor network dynamics in Parkinson's disease. Brain 2015;138:664-678. 